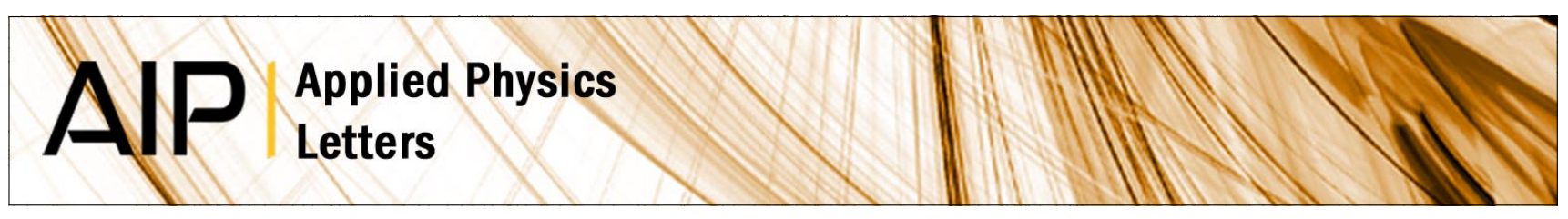

\title{
InGaN/GaN light-emitting diode with a polarization tunnel junction
}

Zi-Hui Zhang, Swee Tiam Tan, Zabu Kyaw, Yun Ji, Wei Liu et al.

Citation: Appl. Phys. Lett. 102, 193508 (2013); doi: 10.1063/1.4806978

View online: http://dx.doi.org/10.1063/1.4806978

View Table of Contents: http://apl.aip.org/resource/1/APPLAB/v102/i19

Published by the American Institute of Physics.

Additional information on Appl. Phys. Lett.

Journal Homepage: http://apl.aip.org/

Journal Information: http://apl.aip.org/about/about_the_journal

Top downloads: http://apl.aip.org/features/most_downloaded

Information for Authors: http://apl.aip.org/authors

\section{ADVERTISEMENT}

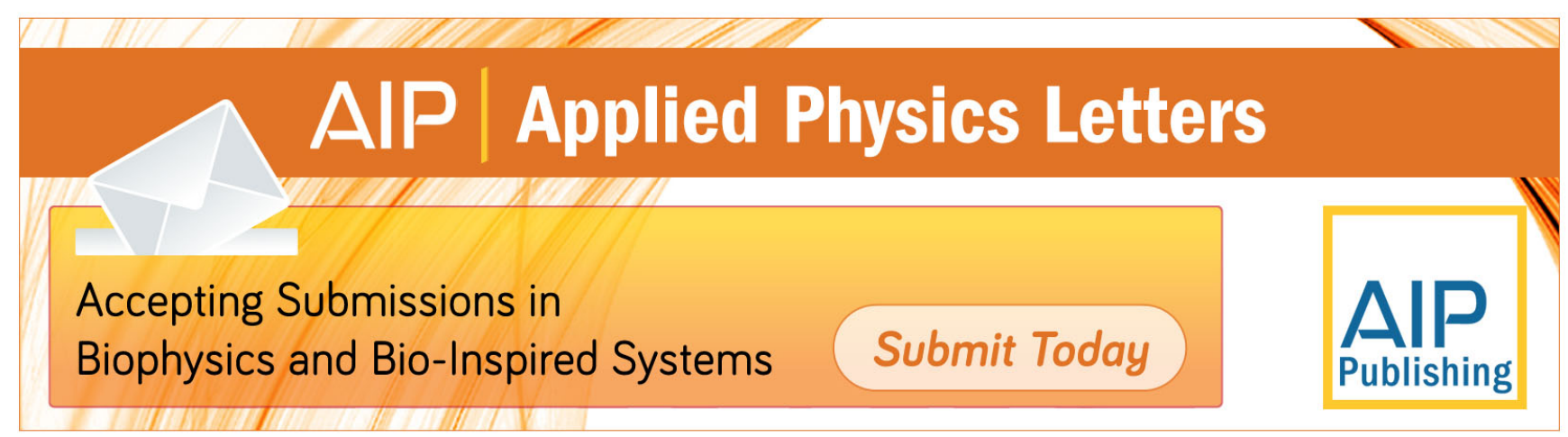




\title{
InGaN/GaN light-emitting diode with a polarization tunnel junction
}

\author{
Zi-Hui Zhang, ${ }^{1}$ Swee Tiam Tan, ${ }^{1}$ Zabu Kyaw, ${ }^{1}$ Yun Ji, ${ }^{1}$ Wei Liu, ${ }^{1}$ Zhengang Ju, ${ }^{1}$ \\ Namig Hasanov, ${ }^{1}$ Xiao Wei Sun, ${ }^{1,2, a)}$ and Hilmi Volkan Demir ${ }^{1,3,4, a)}$ \\ ${ }^{1}$ LUMINOUS! Centre of Excellence for Semiconductor Lighting and Displays, School of Electrical and \\ Electronic Engineering, Nanyang Technological University, 50 Nanyang Avenue, 639798 Singapore \\ ${ }^{2}$ Department of Electronic and Computer Engineering, South University of Science and Technology of China, \\ Shenzhen, Guangdong 518055, China \\ ${ }^{3}$ School of Physical and Mathematical Sciences, Nanyang Technological University, 50 Nanyang Avenue, \\ 639798 Singapore \\ ${ }^{4}$ Department of Electrical and Electronics, Department of Physics, and UNAM-Institute of Material Science \\ and Nanotechnology, Bilkent University, TR-06800 Ankara, Turkey
}

(Received 2 April 2013; accepted 29 April 2013; published online 15 May 2013)

We report InGaN/GaN light-emitting diodes (LED) comprising in situ integrated $\mathrm{p}^{+}-\mathrm{GaN} / \mathrm{InGaN} /$ $\mathrm{n}^{+}-\mathrm{GaN}$ polarization tunnel junctions. Improved current spreading and carrier tunneling probability were obtained in the proposed device architecture, leading to the enhanced optical output power and external quantum efficiency. Compared to the reference InGaN/GaN LEDs using the conventional $\mathrm{p}^{+} / \mathrm{n}^{+}$tunnel junction, these devices having the polarization tunnel junction show a reduced forward bias, which is attributed to the polarization induced electric fields resulting from the in-plane biaxial compressive strain in the thin InGaN layer sandwiched between the $\mathrm{p}^{+}-\mathrm{GaN}$ and ${ }^{+}$-GaN layers. @ 2013 AIP Publishing LLC. [http://dx.doi.org/10.1063/1.4806978]

Significant efforts have been devoted to boosting the optical output power and enhancing the external quantum efficiency (EQE) of $\mathrm{InGaN} / \mathrm{GaN}$ light-emitting diodes (LEDs). ${ }^{1-3}$ These approaches include charge seperation suppression via quantum well engineering, ${ }^{4-6}$ barrier engineering, ${ }^{7-12}$ electron blocking layer (EBL) engineering, ${ }^{13-16}$ and novel epitaxy methods for dislocation density suppression. ${ }^{17,18}$ Recently, these efforts have also been extended to improving the current spreading and, thus, the EQE and output power of InGaN/GaN LEDs. ${ }^{19-21}$ However, the improved current spreading can be achieved either by inserting a resistive layer into the $\mathrm{p}-\mathrm{GaN}$ layer, or increasing the conductivity of the contact layer for p-electrode ${ }^{21}$ For this purpose, the $\mathrm{p}^{+} / \mathrm{n}^{+}$tunnel junction has previously been proposed to enhance the lateral current distribution in InGaN/GaN LEDs. ${ }^{22-26}$ In these devices, the heavy doping in GaN layers induces a strong built-in electric field, which aligns the conduction band of the $\mathrm{n}^{+}-\mathrm{GaN}$ layer with the valence band of the $\mathrm{p}^{+}-\mathrm{GaN}$ layer. ${ }^{27}$ However, this tunnel region is a homojunction with no polarization induced electric fields and yields a low level of tunneling efficiency. Moreover, the additional voltage consumption in the tunnel junction significantly increases the forward voltage of the resulting LED device. Here, different than the previous reports, to enhance the tunneling efficiency and reduce the voltage drop across the tunnel junction, we propose and demonstrate the InGaN/GaN LED integrated with a polarization tunnel junction.

III-nitride epitaxial layers grown along c-orientation are well known to exhibit strong spontaneous polarization and piezo-electric polarization, ${ }^{28}$ which induce positive and negative sheet charges with relatively high densities at the heterojunction interfaces. These charges are able to generate strong electric field resulting in the band bending, similar to the

a)Electronic addresses: HVDEMIR@ntu.edu.sg and EXWSUN@ntu.edu.sg ionized dopants in the $\mathrm{p}^{+} / \mathrm{n}^{+}$homojunctions. Hence, the tunneling probability can be significantly affected by the strong polarization. The polarization tunneling has been investigated for both the metal-face $(\mathrm{Ga} / \mathrm{Al} / \mathrm{In}$-face for $\mathrm{c}+$ growth orientation) and the nitrogen-face ( $\mathrm{N}$-face for $\mathrm{c}-$ growth orientation) IIInitride heterojunctions, ${ }^{29-31}$ and excellent tunneling probability was obtained through those polarized junctions. However, to date, polarization tunneling phenomenon has not been investigated or demonstrated for InGaN/GaN LEDs. Thus, in this work, to understand the effect of the polarization tunnel junction on both the current spreading and the carrier tunneling, we integrated a $\mathrm{p}^{+}-\mathrm{GaN} / \mathrm{InGaN} / \mathrm{n}^{+}-\mathrm{GaN}$ polarization tunnel junction into the InGaN/GaN LED architecture. In proposed device, enhanced optical output power and EQE are observed. This is explained by improved current spreading and increased carrier tunneling enabled by the polarization tunneling.

For our experiments, three types of InGaN/GaN LED samples were grown on c-sapphire substrates by our metalorganic chemical-vapor deposition (MOCVD) system. ${ }^{32}$ The growth was initiated on a $30 \mathrm{~nm}$ thick $\mathrm{GaN}$ nucleation layer. Then, a $4 \mu \mathrm{m}$ thick undoped $\mathrm{GaN}(\mathrm{u}-\mathrm{GaN})$ layer was grown, followed by a $2 \mu \mathrm{m} \mathrm{Si-doped} \mathrm{GaN} \mathrm{(n-GaN)} \mathrm{layer} \mathrm{with} \mathrm{a} \mathrm{dop-}$ ing concentration of $5 \times 10^{18} \mathrm{~cm}^{-3}$. Subsequently, five periods of $\mathrm{In}_{0.15} \mathrm{Ga}_{0.85} \mathrm{~N} / \mathrm{GaN}$ multiple quantum wells (MQWs) were grown. The thickness of the quantum barriers and quantum wells is 12 and $3 \mathrm{~nm}$, respectively. On top of the MQWs, a $25 \mathrm{~nm}$ Mg-doped- $\mathrm{Al}_{0.15} \mathrm{Ga}_{0.85} \mathrm{~N}$ layer was grown as the EBL. After that, a $0.2 \mu \mathrm{m}$ thick $\mathrm{Mg}$-doped $\mathrm{GaN}$ (p-GaN) layer with a hole concentration of $3 \times 10^{17} \mathrm{~cm}^{-3}$ was grown. For the Reference Device [see Fig. 1(a)], a $30 \mathrm{~nm}$ thick heavily $\mathrm{Mg}$-doped $\mathrm{GaN}\left(\mathrm{p}^{+}-\mathrm{GaN}\right)$ layer was finally grown as the p-type contact layer. For our epitaxial wafers, the flow rates of $\mathrm{Cp}_{2} \mathrm{Mg}$ and TMGa are $1.3 \mu \mathrm{mol} / \mathrm{min}$ and $22.0 \mu \mathrm{mol} / \mathrm{min}$, respectively, and the ionization ratio of $\mathrm{Mg}$ dopants at room temperature is $1 \%$ in $\mathrm{GaN}^{33}$ Thus, the ionized $\mathrm{Mg}$ doping concentration in the $\mathrm{p}^{+}-\mathrm{GaN}$ layer is 
(a)

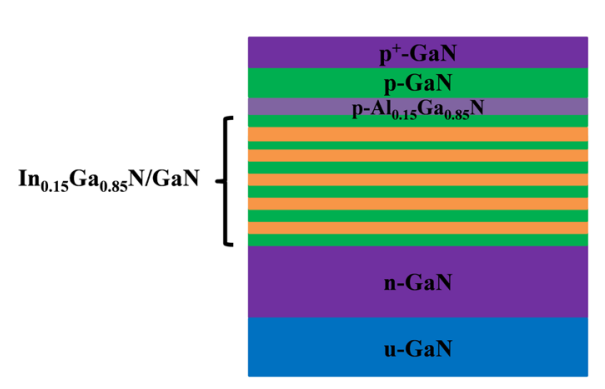

Reference Device (b)

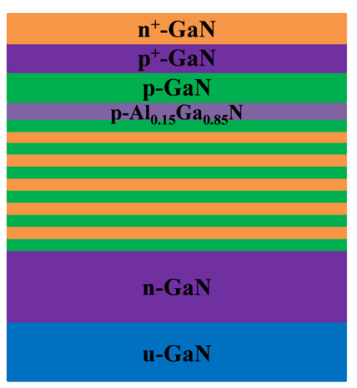

Device A

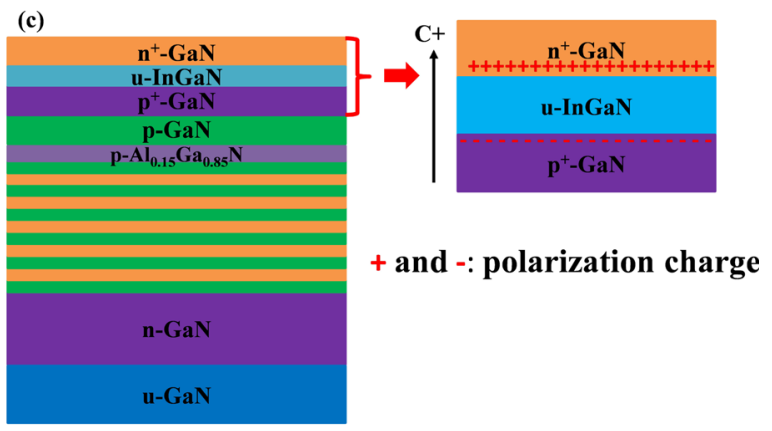

Device B

FIG. 1. Device architectures: (a) Reference Device, (b) Device A with the conventional $\mathrm{p}^{+} / \mathrm{n}^{+}$tunnel junction, and (c) Device B with the polarization tunnel junction.

estimated to be $3 \times 10^{19} \mathrm{~cm}^{-3}$. For Device A with the conventional tunnel junction [see Fig. 1(b)], another $30 \mathrm{~nm} \mathrm{n}^{+}$GaN layer with the $\mathrm{Si}$ doping concentration of $1 \times 10^{20}$ $\mathrm{cm}^{-3}$ was grown on the $\mathrm{p}^{+}-\mathrm{GaN}$ layer. In order to reduce the $\mathrm{Mg}$ diffusion, the following $\mathrm{n}^{+}-\mathrm{GaN}$ layer was grown under the same condition as $\mathrm{p}^{+}-\mathrm{GaN}$, except that $\mathrm{Cp}_{2} \mathrm{Mg}$ was replaced by $\mathrm{SiH}_{4}$. Meanwhile, considering the compensation effect of $\mathrm{Mg}$ dopants, the $\mathrm{n}^{+}-\mathrm{GaN}$ layer was intentionally doped at a higher level than the $\mathrm{p}^{+}-\mathrm{GaN}$ layer. As for Device $B$ with the polarization tunnel junction [see Fig. 1(c)], a $3 \mathrm{~nm}$ thick undoped $\operatorname{In}_{0.15} \mathrm{Ga}_{0.85} \mathrm{~N}$ layer was sandwiched between the $\mathrm{p}^{+}-\mathrm{GaN}$ layer and $\mathrm{n}^{+}-\mathrm{GaN}$ layer. The growth condition for $\mathrm{In}_{0.15} \mathrm{Ga}_{0.85} \mathrm{~N}$ is the same as that for the quantum well region.

After growing these described epi-layers in our MOCVD system, we further fabricated three sets of devicelevel samples. During fabrication, the LED mesa with a chip size of $350 \times 350 \mu \mathrm{m}^{2}$ was patterned by using reactive ion etch (RIE). Indium tin oxide (ITO) of $200 \mathrm{~nm}$ was sputtered as the transparent current spreading layer. Finally, Ti/Au $(30 \mathrm{~nm} / 150 \mathrm{~nm})$ was deposited by e-beam evaporation serving as the p-contact and n-contact.

We also performed numerical simulations to understand the underlying device physics by APSYS, ${ }^{9}$ which selfconsistently solves the Poisson equation, continuity equation, and Schrödinger equation with proper boundary conditions. The self-consistent six-band $k \cdot p$ theory is used to take account of the carrier screening effect in $\mathrm{InGaN}$ quantum wells. ${ }^{34}$ In our simulations, the Auger recombination coefficient is taken to be $1 \times 10^{-30} \mathrm{~cm}^{6} \mathrm{~s}^{-1} .{ }^{35}$ The Shockley-ReadHall (SRH) lifetime for electron and hole is set to be $43 \mathrm{~ns}^{35}$ Meanwhile, a $40 \%$ of the theoretical polarization induced sheet charge density is assumed due to the crystal relaxation through dislocation generation during the growth. ${ }^{28}$ The energy band offset ratio of $\Delta \mathrm{E}_{\mathrm{c}} / \Delta \mathrm{E}_{\mathrm{v}}=70 / 30$ is set in the InGaN/GaN quantum well regions. ${ }^{36}$ The other parameters used in the simulation can be found elsewhere. ${ }^{37}$

Figs. 2(a) and 2(b) show the experimental and simulated injection current as a function of the applied bias. The simulated current-voltage characteristics of the studied devices agree well with the experimental ones. It can be seen from Figs. 2(a) and 2(b) that the Reference Device and Device A (with the conventional $\mathrm{p}^{+} / \mathrm{n}^{+}$tunnel junction) have the lowest and highest forward voltage, respectively. On the other hand, the forward voltage is reduced in Device B when the polarization tunnel junction is used. The improved electrical performance in Device B compared to Device A is attributed to the enhanced tunneling probability $\left[P_{t}\right.$ as shown in Eq. (1)] of the carrers in the $\mathrm{p}^{+}-\mathrm{GaN} / \mathrm{InGaN} / \mathrm{n}^{+}-\mathrm{GaN}$ region

$$
P_{t} \sim \exp \left(-\frac{\pi \times m^{* 1 / 2} \times E_{g}^{3 / 2}}{2 \sqrt{2} e \times \hbar \times E}\right),
$$

where $m^{*}$ is the effective mass of the carriers in the tunnel layer and $E_{g}$ is the energy bandgap of the tunnel region while $E$ is the electric field, which assists the carrier tunneling. ${ }^{27}$

According to Eq. (1), the tunnel region with a small energy bandgap produces a large tunneling probability. Since the InGaN tunnel junction in Device B has a smaller energy bandgap compared to the GaN tunnel junction in Device A, Device B leads to a higher tunneling probability than Device A. ${ }^{30}$ Also, the additional polarization induced electric field in the $\mathrm{p}^{+}-\mathrm{GaN} / \mathrm{InGaN} / \mathrm{n}^{+}-\mathrm{GaN}$ junction further increases the carrier tunneling probability. Fig. 3 shows the calculated
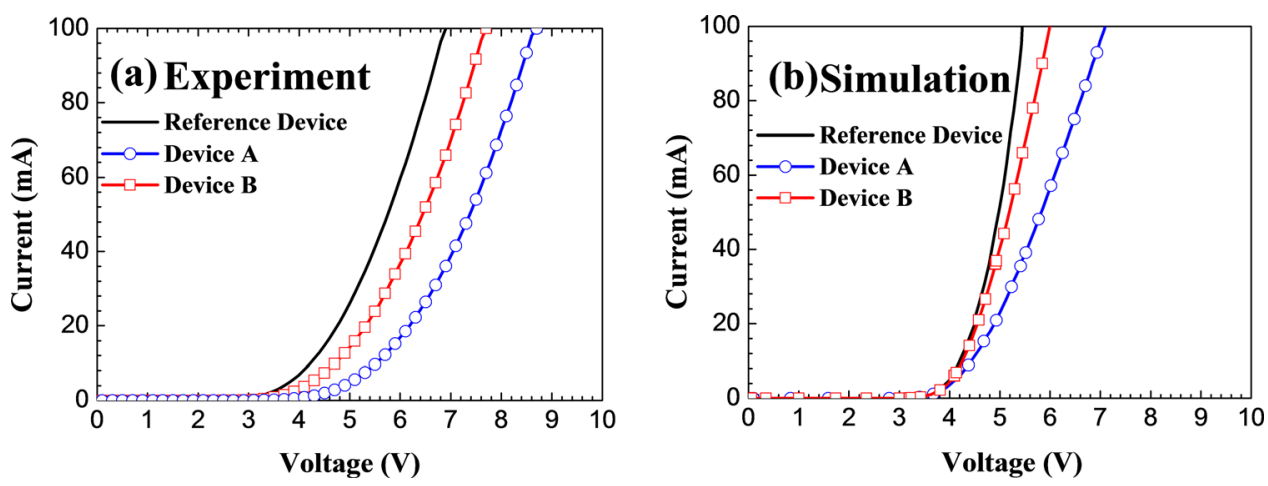

FIG. 2. Injection current versus applied bias: (a) experiment and (b) simulation. 


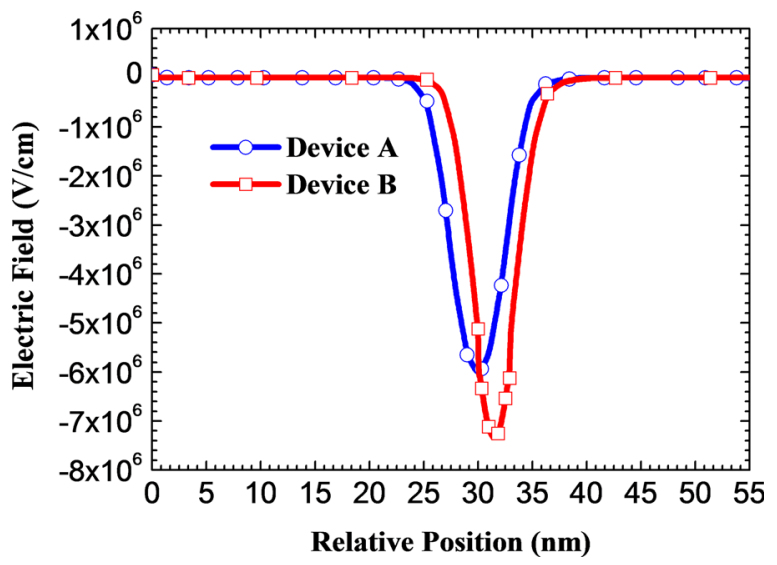

FIG. 3. Electric field profile computed across the tunnel junction at $4.5 \mathrm{~V}$ for Device A and Device B. The positive direction of the electric field is along the growth orientation (i.e., [0001]).

electric fields within the tunnel junction for Device A and Device B. In the $\mathrm{p}^{+}-\mathrm{GaN} / \mathrm{n}^{+}-\mathrm{GaN}$ junction of Device A, besides the field produced by the external applied bias, the additional electric field is generated by the ionized $\mathrm{Si}$ donors in the $\mathrm{n}^{+}-\mathrm{GaN}$ and and $\mathrm{Mg}$ acceptors in the $\mathrm{p}^{+}-\mathrm{GaN}$ layers. Nevertheless, when the InGaN layer is sandwiched between the $\mathrm{p}^{+}-\mathrm{GaN} / \mathrm{n}^{+}-\mathrm{GaN}$ junction in Device $\mathrm{B}$, the polarization charges will be generated as indicated in Fig. 1(c). The polarization induced electric field in the compressive-strained InGaN layer is added as the third electric field component in the tunnel junction. For that, the magnitude of the total electric field in the tunnel junction for Device B is larger than that for Device A, as indicated in Fig. 3. The enhanced electric field, therefore, results in a better carrier tunneling probability and a reduced voltage drop in the tunnel region for Device B when compared to Device A.

Figs. 4(a) and 4(b) present the energy band diagrams of the tunnel junctions for Devices A and B, respectively. We can see that, for both devices, the conduction band of the $\mathrm{n}^{+}$-GaN layer is well aligned with the valance band of the $\mathrm{p}^{+}$-GaN layer. Thus, those electrons in the valance band of the $\mathrm{p}^{+}-\mathrm{GaN}$ layer are able to tunnel into the conduction band of the $\mathrm{n}^{+}$-GaN layer through the forbidden band. With this, holes will be generated in the valance band of the $\mathrm{p}^{+}-\mathrm{GaN}$ layer and then injected into the quantum wells for recombination under the electric field. However, as indicated in Fig. 3 for Device A, the tunnel region consists of two electric fields, i.e., the built-in electric field $\left(E_{b i}\right)$ due to the ionized dopants and the electric field by the external applied bias

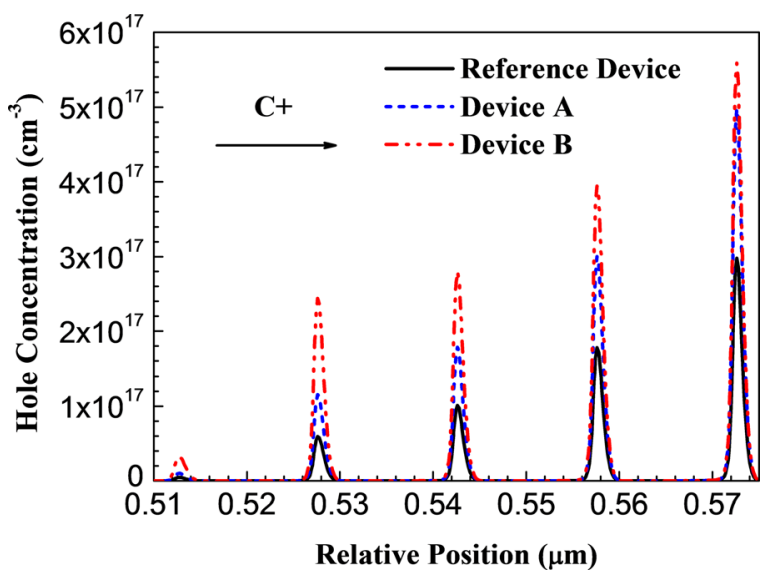

FIG. 5. Hole concentrations in InGaN/GaN MQWs for the Reference Device, Device A, and Device B at $50 \mathrm{~mA}$.

$\left(E_{\text {ext }}\right)$. On the other hand, in Device B, in addition to the $E_{b i}$ and $E_{e x t}$, the polarization induced electric field $\left(E_{s p+p z}\right)$ increases further the overall magnitude of the total electric field. The stronger electric field in Device B promotes the carrier tunneling probability and thus improves the electrical and optical performance.

It should be noted that Device B features a higher forward voltage compared to the Reference Device, as shown both in Fig. 2(a) and 2(b). This is mainly because of two reasons: First, it is difficult to grow high quality crystalline and thick InGaN layer with high indium content on the p-GaN layer. Second, the crystal relaxation may happen during the epitaxial process, and therefore, the actual polarization charge density in the InGaN/GaN hetero-interface could be smaller than the theoretical value. In our case, we assumed a $40 \%$ of the theoretical polarization induced sheet charge density in our simulation. ${ }^{28}$ To assist the tunneling process, we intentionally heavily doped the GaN layers with $\mathrm{Mg}$ and $\mathrm{Si}$ in Device B. However, improvement in the electrical properties using the polarization tunneling without heavily doping is theoretically possible according to the report by Schubert. ${ }^{29}$ The detailed discussion regarding the effect of InGaN thickness and InN fraction on improving the electrical property can further be found in the supplementary material. ${ }^{38}$

Fig. 5 presents the hole concentration across the MQWs for the three devices. It shows that the Reference Device has the smallest hole concentration in each quantum well. In Device A with the $\mathrm{p}^{+} / \mathrm{n}^{+}$-tunnel junction, the hole concentration within the MQWs is increased compared to that in the
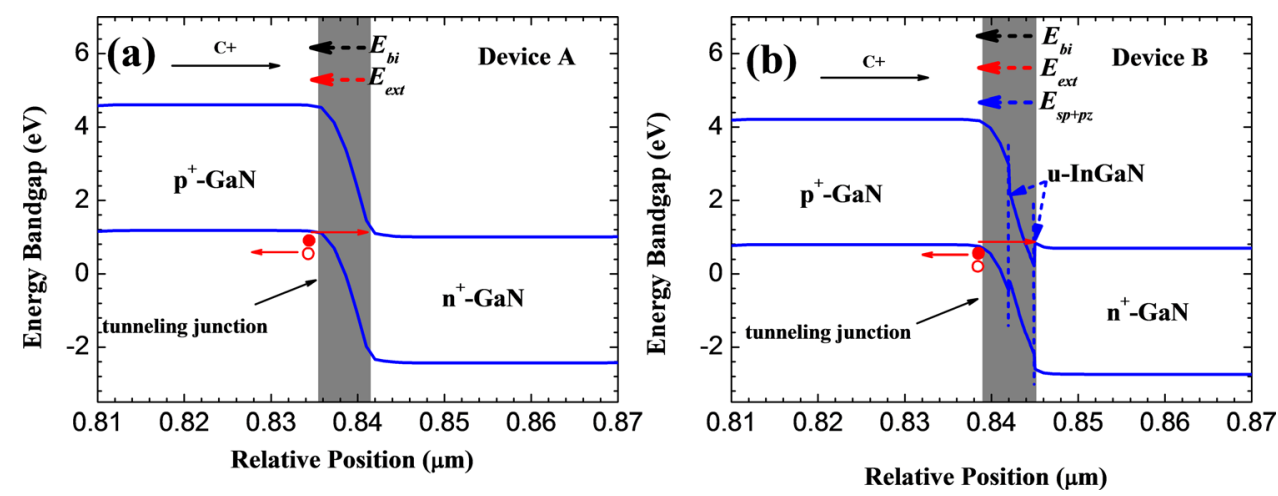

FIG. 4. Energy band diagrams of the tunnel junction for (a) Device A and (b) Device B. 


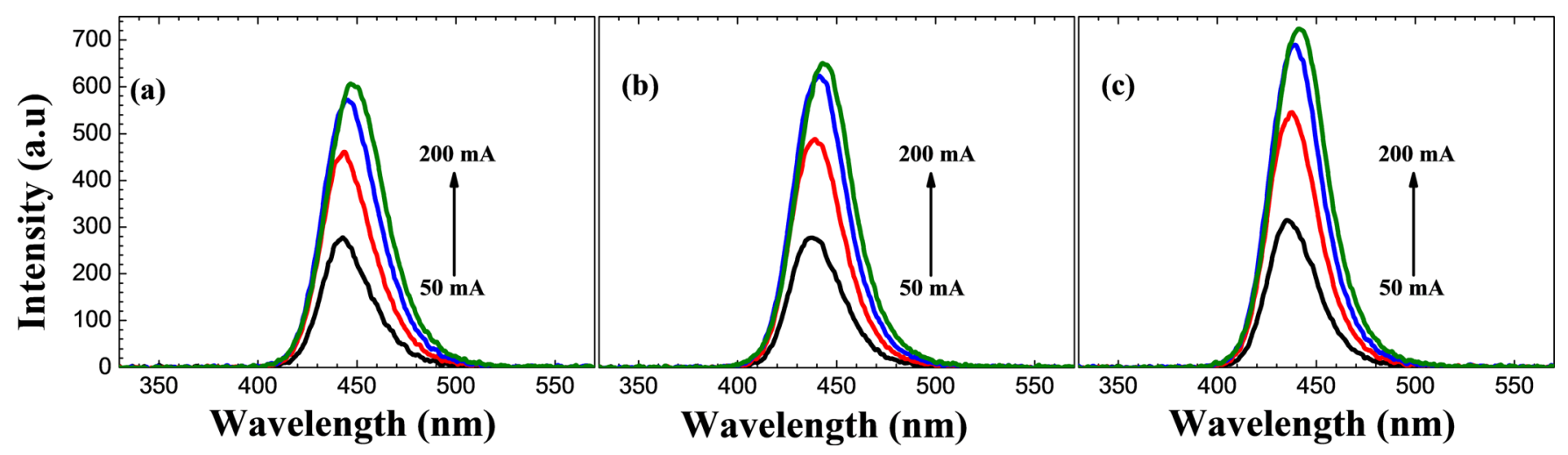

FIG. 6. EL spectra measured from (a) Reference Device, (b) Device A, and (c) Device B.

Reference Device, which is due to an improved current spreading in the $\mathrm{n}^{+}$-GaN layer of Device A. ${ }^{21}$ In the case of Device $B$ with the $\mathrm{p}^{+}-\mathrm{GaN} / \mathrm{InGaN} / \mathrm{n}^{+}-\mathrm{GaN}$ junction, the highest hole concentration in the MQWs is observed, which stems from the improved current spreading effect and higher carrier tunneling probability.

The electroluminescence (EL) spectra measured for the Reference Device, Device A and Device B are shown in Figs. 6(a)-6(c), respectively. We can see that the Reference Device has the lowest EL intensity. With the incorporation of the $\mathrm{p}^{+} / \mathrm{n}^{+}$-tunnel junction (Device A), the emission is improved due to the improved current spreading in the $\mathrm{n}^{+}$-GaN layer. ${ }^{21}$ Meanwhile, the strongest EL emission intensity is obtained from Device B, as shown in Fig. 6(c). The enhanced optical performance in Device B results from the improved current spreading effect ${ }^{21}$ and the enhanced carrier tunneling probability in the polarization tunnel junction. We also observed a redshift of the emission wavelength as the injection current increases for all the three devices, and this is due to the increased junction temperature during the testing. ${ }^{39}$

The optical output power and EQE were measured and are presented in Fig. 7. Correspondingly, we observed the lowest optical output power and EQE from the Reference Device. Because of the improved current spreading effect, the optical output power in Device A is increased by $8.46 \%$ and $9.34 \%$ at 20 and $200 \mathrm{~mA}$, respectively, as compared to the Reference Device. For Device B, an enhancement of $18.08 \%$ and $20.87 \%$ for the optical output power is realized

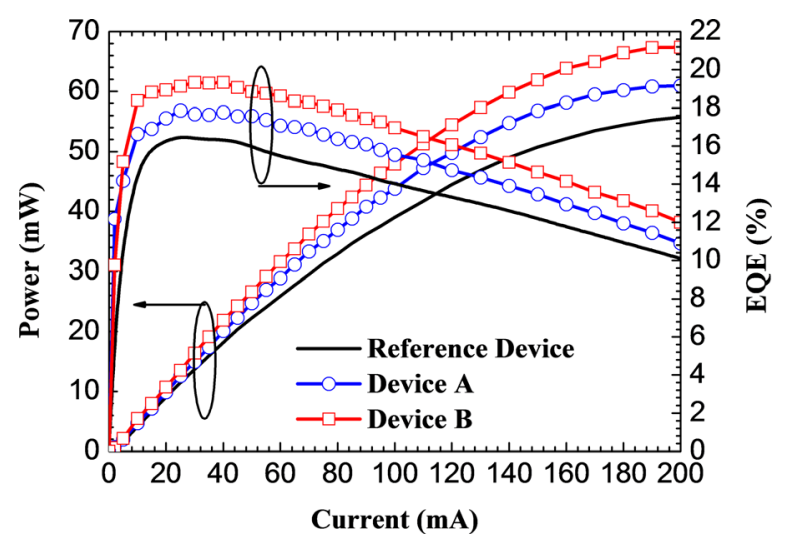

FIG. 7. Experimental optical output power and $\mathrm{EQE}$ as a function of the injection current for the Reference Device, Device A, and Device B. at 20 and $200 \mathrm{~mA}$, respectively, when compared to the Reference Device.

In conclusion, the InGaN/GaN LED with a $\mathrm{p}^{+}-\mathrm{GaN} /$ $\mathrm{InGaN} / \mathrm{n}^{+}-\mathrm{GaN}$ polarization tunnel junction has been proposed and studied in this work. Our findings indicate that the polarization induced electric field in the $\mathrm{p}^{+}-\mathrm{GaN} / \mathrm{InGaN} /$ $\mathrm{n}^{+}$-GaN polarization tunnel junction further increases the magnitude of the total electric field, and thus enhances the electrical performance for the proposed device when compared to the InGaN/GaN LED using the conventional $\mathrm{p}^{+} /$ $\mathrm{n}^{+}$-GaN tunnel junction. Moreover, the increased magnitude of the electric field within the tunnel junction also increases the carrier tunneling probability, and promotes the carrier injection into the MQWs and therefore enhances the optical output power and EQE for the proposed device.

This work was supported by the National Research Foundation of Singapore under Grant Nos. NRF-CRP-62010-2 and NRF-RF-2009-09 and the Singapore Agency for Science, Technology and Research (A*STAR) SERC under Grant No. 112120 2009. The authors would like to thank Ke Zheng for the deposition of indium tin oxide (ITO).

${ }^{1}$ M. H. Crawford, IEEE J. Sel. Top. Quantum Electron. 15, 1028 (2009).

${ }^{2}$ N. Tansu, H. Zhao, G. Liu, X. H. Li, J. Zhang, H. Tong, and Y. K. Ee, IEEE Photon. J. 2, 241 (2010).

${ }^{3}$ S. T. Tan, X. W. Sun, H. V. Demir, and S. P. DenBaars, IEEE Photon. J. 4, 613 (2012).

${ }^{4}$ D. F. Feezell, J. S. Speck, S. P. DenBaars, and S. Nakamura, J. Disp. Technol. 9, 190 (2013).

${ }^{5}$ H. Zhao, G. Liu, J. Zhang, J. D. Poplawsky, V. Dierolf, and N. Tansu, Opt. Express 19, A991 (2011).

${ }^{6}$ J. Zhang and N. Tansu, IEEE Photon. J. 5, 2600111 (2013).

${ }^{7}$ X. F. Ni, Q. Fan, R. Shimada, U. Ozgur, and H. Morkoc, Appl. Phys. Lett. 93, 171113 (2008).

${ }^{8}$ J. K. Sheu, G. C. Chi, and M. J. Jou, IEEE Photon. Technol. Lett. 13, 1164 (2001).

${ }^{9}$ Z.-H. Zhang, S. T. Tan, Z. Ju, W. Liu, Y. Ji, Z. Kyaw, Y. Dikme, X. W. Sun, and H. V. Demir, J. Disp. Technol. 9, 226 (2013).

${ }^{10}$ Y. Ji, Z.-H. Zhang, S. T. Tan, Z. G. Ju, Z. Kyaw, N. Hasanov, W. Liu, X. W. Sun, and H. V. Demir, Opt. Lett. 38, 202 (2013).

${ }^{11}$ G. Liu, J. Zhang, C. K. Tan, and N. Tansu, IEEE Photon. J. 5, 2201011 (2013).

${ }^{12}$ H. P. Zhao, G. Liu, J. Zhang, R. A. Arif, and N. Tansu, J. Disp. Technol. 9, 212 (2013).

${ }^{13}$ Y. K. Kuo, J. Y. Chang, and M. C. Tsai, Opt. Lett. 35, 3285 (2010).

${ }^{14}$ Y.-A. Chang, J.-Y. Chang, Y.-T. Kuo, and Y.-K. Kuo, Appl. Phys. Lett. 100, 251102 (2012).

${ }^{15}$ J. H. Lee, IEEE Electron Device Lett. 31, 455 (2010).

${ }^{16}$ L. Zhang, K. Ding, J. C. Yan, J. X. Wang, Y. P. Zeng, T. B. Wei, Y. Y. Li, B. J. Sun, R. F. Duan, and J. M. Li, Appl. Phys. Lett. 97, 062103 (2010). 
${ }^{17}$ Y. K. Ee, J. M. Biser, W. Cao, H. M. Chan, R. P. Vinci, and N. Tansu, IEEE J. Sel. Top. Quantum Electron. 15, 1066 (2009).

${ }^{18}$ Y. Li, S. You, M. Zhu, L. Zhao, W. Hou, T. Detchprohm, Y. Taniguchi, N. Tamura, S. Tanaka, and C. Wetzel, Appl. Phys. Lett. 98, 151102 (2011).

${ }^{19}$ H. Y. Ryu and J. I. Shim, Opt. Express 19, 2886 (2011).

${ }^{20}$ H. Kim, S. J. Park, and H. Hwang, IEEE Trans. Electron Devices 48, 1065 (2001).

${ }^{21}$ Z.-H. Zhang, S. T. Tan, W. Liu, Z. Ju, K. Zheng, Z. Kyaw, Y. Ji, N. Hasanov, X. W. Sun, and H. V. Demir, Opt. Express 21, 4958 (2013).

${ }^{22}$ S. R. Jeon, M. S. Cho, M. A. Yu, and G. M. Yang, IEEE J. Sel. Top. Quantum Electron. 8, 739 (2002).

${ }^{23}$ S. R. Jeon, Y. H. Song, H. J. Jang, K. S. Kim, G. M. Yang, S. W. Hwang, and S. J. Son, Phys. Status Solidi A 188, 167 (2001).

${ }^{24}$ S. R. Jeon, Y. H. Song, H. J. Jang, G. M. Yang, S. W. Hwang, and S. J. Son, Appl. Phys. Lett. 78, 3265 (2001).

${ }^{25}$ C. M. Lee, C. C. Chuo, I. L. Chen, J. C. Chang, and J. I. Chyi, IEEE Electron Device Lett. 24, 156 (2003).

${ }^{26}$ T. Takeuchi, G. Hasnain, S. Corzine, M. Hueschen, R. P. Schneider, C. Kocot, M. Blomqvist, Y. L. Chang, D. Lefforge, M. R. Krames, L. W. Cook, and S. A. Stockman, Jpn. J. Appl. Phys., Part 2 40, L861 (2001).

${ }^{27}$ S. M. Sze, Physics of Semiconductor Devices, 2nd ed. (John Wiley \& Sons, Inc., 1981).
${ }^{28}$ V. Fiorentini, F. Bernardini, and O. Ambacher, Appl. Phys. Lett. 80, 1204 (2002).

${ }^{29}$ M. F. Schubert, Phys. Rev. B 81, 035303 (2010).

${ }^{30}$ S. Krishnamoorthy, D. N. Nath, F. Akyol, P. S. Park, M. Esposto, and S. Rajan, Appl. Phys. Lett. 97, 203502 (2010).

${ }^{31}$ J. Simon, Z. Zhang, K. Goodman, H. L. Xing, T. Kosel, P. Fay, and D. Jena, Phys. Rev. Lett. 103, 026801 (2009).

${ }^{32}$ Z. G. Ju, S. T. Tan, Z.-H. Zhang, Y. Ji, Z. Kyaw, Y. Dikme, X. W. Sun, and H. V. Demir, Appl. Phys. Lett. 100, 123503 (2012).

${ }^{33}$ H. Tokunaga, A. Ubukata, Y. Yano, A. Yamaguchi, N. Akutsu, T. Yamasaki, and K. Matsumoto, J. Cryst. Growth 272, 348 (2004).

${ }^{34}$ H. Zhao, R. A. Arif, Y. K. Ee, and N. Tansu, IEEE J. Quantum Electron. 45, 66 (2009).

${ }^{35}$ M. Meneghini, N. Trivellin, G. Meneghesso, E. Zanoni, U. Zehnder, and B. Hahn, J. Appl. Phys. 106, 114508 (2009).

${ }^{36}$ J. Piprek and S. Nakamura, IEEE Proc. Optoelectron. 149, 145 (2002).

${ }^{37}$ I. Vurgaftman and J. R. Meyer, J. Appl. Phys. 94, 3675 (2003).

${ }^{38}$ See supplementary material at http://dx.doi.org/10.1063/1.4806978 for the effect of InGaN thickness and InN fraction on the electrical property of the $\mathrm{InGaN} / \mathrm{GaN}$ LED with $\mathrm{p}^{+}-\mathrm{GaN} / \mathrm{InGaN} / \mathrm{n}^{+}-\mathrm{GaN}$ polarization tunnel junctions.

${ }^{39}$ Z. Gong, S. Jin, Y. Chen, J. McKendry, D. Massoubre, I. M. Watson, E. Gu, and M. D. Dawson, J. Appl. Phys. 107, 013103 (2010). 